\title{
Late Niemann-Pick disease with neurovisceral storage: a classification problem
}

\author{
J McFARLANE, L MURRAY,* K BRADBURY, P N COWEN \\ From the Departments of Pathology, and *Forensic Medicine, University of Leeds
}

SUMMARY A 51 year old man presented in 1969 with slowly progressive cerebellar ataxia of unknown origin. He was admitted to hospital aged 68 after a fall, and a ruptured spleen was removed at laparotomy. Histological analysis of the spleen suggested Niemann-Pick disease, which was subsequently confirmed. He deteriorated and died of bronchopneumonia shortly afterwards: subdural haemorrhage with storage material in neurones was found at necropsy. This late onset case of Niemann-Pick disease with neurovisceral storage is unusual and may represent a variant.

Since the first cases of Niemann-Pick disease were described ${ }^{1-2}$ it is now known that it takes several forms which can be distinguished on the basis of clinical history and which organs are affected. ${ }^{3}$ We describe a case which does not seem to conform to this pattern.

\section{Case report}

A 51 year old caucasian man, married with five healthy children and no family history of neurological disease or a storage disorder, first noted clumsiness and unsteadiness when walking in 1969. He was found to have cerebellar ataxia, spastic dysarthria, and pallor of the right optic disc. Reflexes were normal and there was no nystagmus nor sensory or motor deficit. Electromyography showed slight slowing of sensory conduction in all four limbs. General physical examination showed no other abnormalities and no definite diagnosis was made. A year later he had to retire early and 10 years later, in 1980, he developed a defective upgaze and left upper motor neurone facial weakness. A computed tomography scan indicated cerebral atrophy. He was reassessed in 1981 when cogwheel rigidity of both wrists, a positive glabellar tap, and truncal ataxia were found. During the progression of the disease he had become more ataxic, sustaining many injuries as a result of falls, including fractures of the hip, arm, and second cervical vertebra.

In 1985, when he was 68 years old, he was admitted as an emergency with a history of acute abdominal pain after falling at home. Laparotomy showed a

Accepted for publication 26 January 1988 ruptured spleen which was removed. It weighed $420 \mathrm{~g}$ and was torn and haemorrhagic. Microscopical examination showed collections of foamy macrophages in the red pulp (fig 1) containing fat which stained with Sudan IV. Sphingomyelin was shown by the alkaline hydrolysis modification of Baker's acid haematein stain. Niemann-Pick disease was diagnosed and confirmed by electron microscopy of the spleen which showed histiocytes containing typical dense multilamellar bodies. ${ }^{4}$

The patient was discharged with arrangements made for assessment of skin fibroblast sphingomyelinase activity. Before this could be performed, he was admitted to another hospital several weeks later with severe dysarthria, generalised muscle wasting, and bilateral extensor plantar responses; he deteriorated and died of bronchopneumonia five days later.

\section{Pathology}

The body was that of an emaciated man, 1.75 metres in height, and weighing $38 \mathrm{~kg}$, with scattered bruises on the limbs and a large sacral pressure sore. The only clinically important finding internally, apart from bronchopneumonia, was a large subdural haematoma more than a week old over the right frontoparietal region, which had compressed the brain. The brain stem and cerebellum appeared normal but there was bilateral uncal herniation.

Microscopical examination of the brain showed a number of vacuolated neurones, particularly in the brain stem and cerebellum which contained acid haematein-negative storage material-and therefore unlikely to be sphingomyelin. Foamy macrophages 


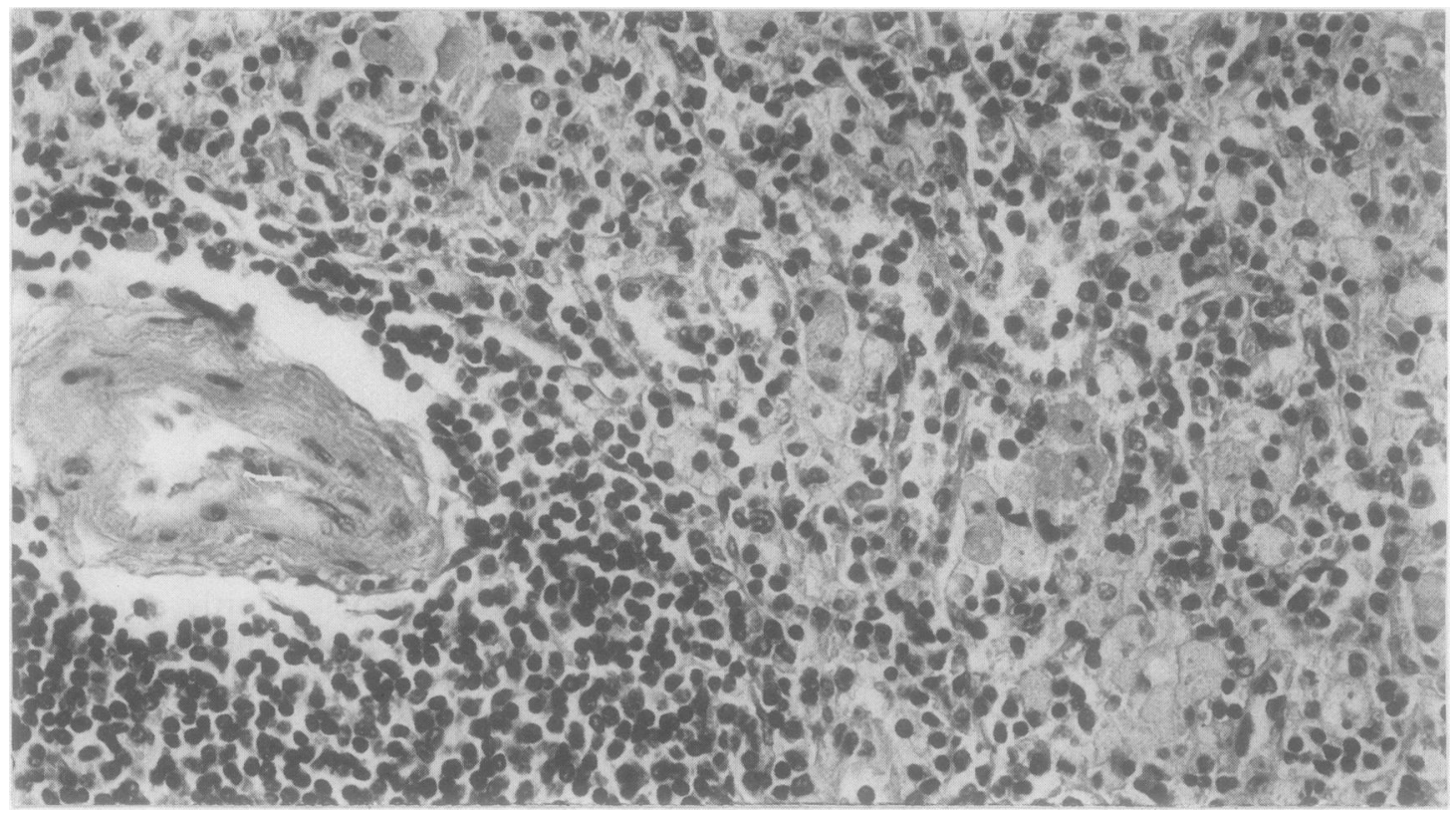

Fig 1 Section of spleen showing foamy histiocytes. (Haematoxylin and eosin.)

similar to those seen in the spleen were also present in the bone marrow but none was found in the liver or other viscera. Marrow histiocytes containing ceroid material which gives a blue-green colour (so called "sea-blue histiocytes") have been reported in Niemann-Pick disease, ${ }^{5}$ but these were not seen in this case. The foamy cells of the marrow had uniform granules and did not contain the nuclear fragments previously described in group II patients. ${ }^{6}$

Samples from four areas of the spleen removed at operation were subjected to total lipid extraction ${ }^{7}$ and separation by thin layer chromatography; the plates developed in chloroform/methanol/ammonia/water (65:35:2:2, by volume). The lipids were detected with concentrated $\mathrm{H}_{2} \mathrm{SO}_{4}$ at $120^{\circ} \mathrm{C}$ or, in the case of cholinecontaining lipids, bismuth nitrate reagent. For chemical analysis the lipids were detected by iodine vapour and spots identified by comparison with cochromatogrammed standards. Simple lipids were eluted from silica gel with chloroform/methanol (1:1, $\mathrm{vol} / \mathrm{vol}$ ) and phospholipids by the method of De Bohner et al. ${ }^{8}$ Phospholipid phosphorus was determined by the method of Bartlett ${ }^{9}$ and cholesterol by the Lieberman and Burchard reaction.

Thin layer chromatography of the patient's spleen lipid extract showed a pronounced increase in sphingomyelin over that seen in two normal subjects (fig 2). Neutral lipids, including cholesterol, were also increased. Analysis supported the chromatography results (table), showing a more than 10-fold increase in spleen sphingomyelin and also a $50 \%$ increase in cerebral cortex and a $25 \%$ increase in medulla. Cerebral cholesterol was also increased. The absence of a concomitant increase in spleen ethanolamine and choline phosphoglycerides has parallels with a spleen lipid pattern reported from a late onset case. ${ }^{10}$

\section{Discussion}

Crocker ${ }^{11}$ divided Niemann-Pick disease into four types:

Type $A$ is the "classical" form and presents in early

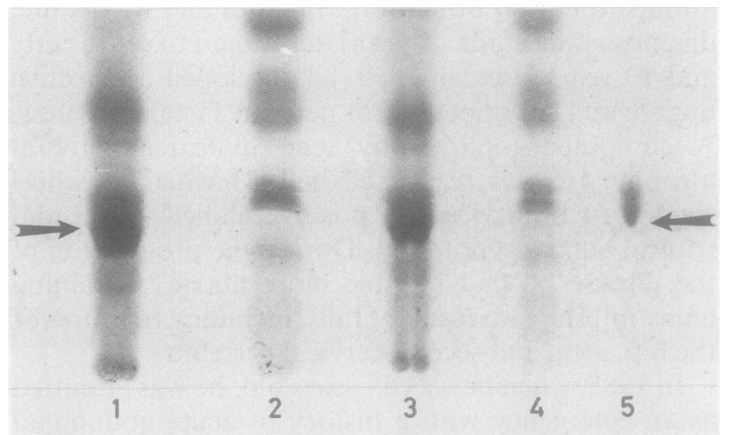

Fig 2 Chromatogram of spleen lipids. Key to lanes: 1 , Niemann-Pick; 2, normal; 3, Niemann-Pick, five-fold dilution; 4, normal, five-fold dilution; 5 , sphingomyelin standard. Sphingomyelin spots are arrowed. 
Table Lipid composition of spleen and cerebrum expressed as percentage of dry weight

\begin{tabular}{llll}
\hline & Spleen & $\begin{array}{l}\text { Cerebral } \\
\text { cortex }\end{array}$ & $\begin{array}{l}\text { Cerebral } \\
\text { medulla }\end{array}$ \\
\hline Total cholesterol & $2 \cdot 1(1 \cdot 3,1 \cdot 0)^{*}$ & $6 \cdot 3(5 \cdot 0,4 \cdot 7)^{*}$ & $16 \cdot 1(14 \cdot 7)^{*}$ \\
$\begin{array}{l}\text { Sphingomyelin } \\
\text { Choline }\end{array}$ & $8 \cdot 2(0 \cdot 5,0 \cdot 7)$ & $2 \cdot 5(1 \cdot 7,1 \cdot 5)$ & $5 \cdot 2(4 \cdot 2,4 \cdot 0)$ \\
$\begin{array}{l}\text { phosphoglycerides } 1 \cdot 1(1 \cdot 3,1 \cdot 4) \\
\text { Ethanolamine } \\
\text { phosphoglycerides } 0.9(0 \cdot 6,0 \cdot 6)\end{array}$ & $11 \cdot 6(11 \cdot 3,11 \cdot 5 \cdot 9)$ & $4 \cdot 9(5 \cdot 0,5 \cdot 3)$ \\
\hline
\end{tabular}

*Figures in parentheses represent data from two control subjects aged 59 and 71 years

infancy with hepatosplenomegaly, failure to thrive, and neurological deterioration. There is a rapid downhill course with death usually before the age of 2 years. Type $B$ cases have hepatosplenomegaly and heavy visceral disease, but no nervous disease, and occur from infancy through childhood.

Type $C$ is similar to $\mathrm{A}$ in that there is both visceral and central nervous system involvement, but presentation is later in childhood or in early adult life and survival is prolonged.

Type $D$, the Nova Scotian variant, is similar to type C but is believed to be a genetically isolated form of it.

Biochemical differences have been found between these groups. Decreased sphingomyelinase activity in type A has been reported ${ }^{12}$ and confirmed by Schneider and Kennedy, ${ }^{13}$ who also found evidence of a defect of this enzyme in type B, but that types $C$ and $D$ cases had normal sphingomyelinase activity. An atypical group of adult patients who were clinically type $C$ but who showed sphingomyelinase deficiency was termed type 'E'. ${ }^{14}$

Type $C$ patients show pronounced accumulation of sphingomyelin in the spleen similar to that seen in types $\mathrm{A}$ and $\mathrm{B}$, but in contrast to those, liver sphingomyelin is usually only slightly raised. Type $\mathrm{C}$ patients also show neuronal storage but it has been shown that the storage material is not sphingomyelin; its identity is at present unknown. ${ }^{15}$

The evidence that types $C$ and $D$ are distinct from type $A$ and $B$ and the need to accommodate adult forms led to the reclassification of Niemann-Pick disease at an international symposium in Prague $^{16}$ as follows: the new group I includes types $A$ and $B$, to which are added the group $\mathrm{E}$ cases. Types $\mathrm{C}$ and $\mathrm{D}$ now constitute group II, which is thought to have a different biochemical basis from group I.

Our case could not have been possible type B or D. It was unlike type $C$ : brain sphingomyelin in $C$ is normal while in our case it was raised but not by as much as is usually found in type A. Unlike type $C$, our patient presented in late middle age, and type $C$ is usually associated with an age of 10 years or less. ${ }^{6}$ Furthermore, the pattern of organ disease was atypical of $\mathrm{C}$ cases as vacuoles rich in sphingomyelin in liver were absent and no inclusion bodies were found in the marrow. The anomaly in our case is that in spite of the above, neuronal inclusion bodies consistent with type $\mathrm{C}$ were present. While the nature of the inclusion bodies in type $\mathrm{C}$ cases is unknown, an increase in ceramide hexoside and monosialogangliosides ${ }^{17}$ and the presence of Bis-(monoacylglycero)-phosphate ${ }^{15}$ may account for some of the neuronal deposits. In contrast, the neuronal deposits in type A cases consist of sphingomyelin and cholesterol. ${ }^{18}$ While the neuronal deposits seen in our case had the appearance of enlarged lysosomes, we cannot confirm that they represented the increase in brain sphingomyelin found chemically. The fact that the lipid changes were confined to cholesterol and sphingomyelin and did not extend to choline and ethanolamine phosphoglycerides, which are common non-specific storage substances, confirms that our case represents Niemann-Pick disease. The increase of brain lipids was similar to that seen in type A patients; nevertheless, this case suggests a type $C$ pattern but with an increase in brain sphingomyelin and cholesterol. This unusual accumulation of brain lipid may be associated with the extremely late age of onset. With the increasing diagnosis of cases of late onset Niemann-Pick disease, this current case may not be unique and may represent a distinct variant of type $C$.

We are indebted to $\operatorname{Dr} M$ Parsons, who kindly permitted us to use his clinical records, and to Dr J M Mackenzie, who made a detailed examination of the brain. Miss D Render gave us secretarial assistance.

\section{References}

1 Niemann A. Ein unbekanntes Krankheitsbild. Jahrbuch für kinderheilkunde. 1914;79:1-10.

2 Pick L. Über die lipoidzelligen splenohepatomegalie Typus Niemann-Pick als Stoffwechselerkrankung. Med Klin 1927; 23:1483-8.

3 Crocker AC, Farber S. Niemann-Pick disease: a review of eighteen patients. Medicine 1958;37:1-95.

4 Long RG, Lake BD, Pettit JE, Scheuer PJ, Sherlock S. Adult Niemann-Pick disease: its relationship to the syndrome of seablue histiocyte. Am J Med 1977;62:627-35.

5 Dewhurst N, Besley GJN, Finlayson NDC, Parker AC. Sea-blue histiocytes in a patient with chronic non-neuropathic NiemannPick disease. J Clin Pathol 1979;32:1121-7.

6 Lake BD. Lysosomal enzyme deficiencies. In: Adams JH, Corsellis JAN, Dochen LW, eds. Neuropathology. 4th ed. 1984:491-572.

7 Folch J, Lees M, Sloane Stanley GH. A simple method for the isolation and purification of total lipide from animal tissues. $J$ Biol Chem 1957;226:497-509.

8 De Bohner LS, Soto EF, De Cohan T. Quantitative analysis of phospholipids by thin layer chromatography. J Chromatography 1965;17:513-9.

9 Bartlett ER. Phosphorus assay in column chromatography. J Biol Chem 1959;234:466-8.

10 Pilz H. Niemann-Picksche Krankheit im Erwachsenenalter. 
Deutsche Med Wochenschr 1970;95:1905-10.

11 Croker AC. The cerebral defect in Tay-Sachs disease and Niemann-Pick disease. $J$ Neurochem 1961;7:69-80.

12 Brady RO, Kanfer JN, Mock MB, Rickson DS. The metabolism of sphingomyelin II. Evidence of an enzymatic deficiency in Niemann-Pick disease. Proc Natl Acad Sci USA 1966;55:366-9.

13 Schneider PB, Kennedy EP. Sphingomyelinase in normal human spleens and in spleens from subjects with Niemann-Pick disease. J Lipid Res 1967;8:202-9.

14 Fredrickson DS, Sloan HR. Sphingomyelin lipidoses: NiemannPick disease. In: The Metabolic basis of inherited disease Stanbury JB, Wyngaarden JB, Fredrickson DS, eds. 3rd ed. New York: McGraw-Hill, 1972:783-807.

15 Seng PN, Debuch H, Witter B, Wiedemann H-R. Bis (monoacyglycerin) phosphorsaure-vermehrung bei sphingomyelinose (M. Niemann-Pick?) Hoppe-Seyler's Zeitschrift für Physiolische
Chemie 1971;352:280-8.

16 Elleder M, Jirasek A. Niemann-Pick disease. Acta Univ Carol Med Monogr Praha 1983;29:259-67.

17 Dawson E, Matalon R, Stein AO. Lactosylceramidosis: lactosylceramide galatosyl hydrolase deficiency and accumulation of lactosylceramide in cultured skin fibroblasts. $J$ Paediatr 1971;79:423-9.

18 Kamoshita S, Aron AM, Suzuki K, Suzuki K. Infantile Niemann-Pick disease. A chemical study with isolation and characterisation of membranous cytoplasmic bodies and myelin. Am J Dis Child 1969;117:379-94.

Requests for reprints to: Dr P N Cowen, Department of Pathology, University of Leeds, Leeds LS2 9JT, England. 